\title{
Vaccine Hesitancy Narratives
}

\author{
Johanna T. Crane, Kara Simpson, Jennifer Breznay,
}

Ashley L. Stewart, David N. Hoffman*

\section{INTRODUCTION}

In this collection of narratives, the authors describe their own experiences with and reflections on healthcare worker vaccine hesitancy. The narratives explore each author's engagement with different communities experiencing vaccine hesitancy, touching on reasons for hesitancy, proposed solutions, and legal aspects. Author's names appear above their narratives.

Keywords: Vaccine Hesitancy, Healthcare Workers, COVID-19, Emergency Approval, Vaccine Mandate, Medical Distrust, Bioethics

I. Johanna T. Crane

Vaccine hesitancy, defined as "a delay of acceptance or refusal of vaccination despite the availability of vaccination services," ${ }^{1}$ is a worldwide but locally shaped phenomenon that pre-dates the COVID-19 pandemic. ${ }^{2}$ Contrary to some portrayals, vaccine hesitancy is not the same as the more absolute antivaccination stance, or what some call "anti-vax." Many people who are hesitant are not ideologically opposed to vaccines. Hesitancy is also sometimes framed as anti-science, yet reluctance to vaccinate is often about managing risk, trustworthiness, and doubt in the context of uncertainty; it represents an effort to "talk back to science" about unaddressed needs and concerns. ${ }^{3}$

In the US, the newness of the vaccines, the unprecedented speed at which they were developed, and their remaining under emergency use authorization at first complicated public confidence. Political polarization

* Johanna T. Crane, Ph.D., Anthropologist, Associate Professor, Alden March Bioethics Institute

Kara Simpson, LCSW-R, Director of Social Work, Behavioral Health Service, NYC H+H Jacobi

Jennifer Breznay, MD MPH, Program Director Division of Geriatrics, Co-Chair, Bioethics Committee, Maimonides Medical Center, Brooklyn, NY

Ashley L. Stewart, Infection Prevention Coordinator, Carthage Area Hospital

David N. Hoffman, JD, Lecturer in Bioethics, Columbia University. General Counsel, Claxton Hepburn Medical Center.

(C) 2021 Hoffman et al. This is an open access article distributed under the terms of the Creative Commons Attribution License, which permits unrestricted use, distribution, and reproduction, provided the original author and source are credited. 
and racial and social inequality shape vaccine acceptance and public distrust as well. While vaccine acceptance has increased in the months since the vaccines first became available, many eligible individuals have not yet been vaccinated, including a significant number of healthcare workers. ${ }^{4}$

Vaccine hesitancy among healthcare workers may seem surprising, especially given their frontline experience - I confess that it surprised me at first. But when I began interviewing health care workers for a study on COVID vaccine roll-out at community health centers, I learned to take a more complex view. Although the study was focused on patient vaccine access, ${ }^{5}$ many of the frontline health care workers we spoke with also described hesitancy among some of their colleagues (and, in a few cases, themselves). From these conversations, I learned that these "healthcare heroes" are also regular people and members of communities. Their concerns about COVID vaccination often reflect the prevailing concerns advanced in their communities, such as worries about vaccine side effects and safety. Like other workers, some fear missing work and losing income, as not all healthcare employers offer paid time off for vaccination or recovery. (Importantly, reluctance to vaccinate is highest among healthcare workers in lower-paid positions with little job security, such as clerks, housekeepers, patient care assistants, and home health aides. $)^{6}$ For some healthcare workers of color, the protection offered by the vaccine sits in tension with both current and historical experiences of medical abuse and neglect. Some interviewees, fully vaccinated themselves, rejected the framework of "hesitancy" entirely, arguing that Black and Brown reluctance to be vaccinated first should be understood through the lens of "self-protection".

Due to the nature of their work, healthcare workers have faced great social pressure to vaccinate and vaccinate first. This is understandable, given that vaccination against COVID-19 protects not only workers themselves but aligns with the ethical duty to prevent harm to patients by reducing the risk of transmission in healthcare settings. When the FDA approved COVID-19 vaccines under emergency use authorization in December 2020, many healthcare workers were extremely grateful to be designated " $1 a$ " - the first group prioritized to receive the shots. ${ }^{7}$ For many bioethicists, prioritization of healthcare workers represented a recognition of the extreme risks that many front-line workers had endured since the onset of the pandemic, including critical shortages in PPE. But it is important to remember that for some workers, going first may have felt like serving as guinea pigs for new vaccines that had yet to be granted full FDA approval. For these individuals, the expectation that they would vaccinate first may have felt like an additional risk rather than a reward.

Healthcare workers who are hesitant to vaccinate may feel ashamed or be subject to shaming by others; ${ }^{8}$ this may make it difficult to discuss their concerns in the workplace. Throughout the pandemic, healthcare workers have been lauded as "heroes", and some healthcare employers have promoted vaccination among their workforce as a "heroic" action. This messaging implies that waiting to vaccinate is shameful or cowardly and is echoed in opinion pieces and op-eds describing unvaccinated people as "selfish" or "free riders." ${ }^{\prime \prime}$

By fostering the proper dialogue, we can respond respectfully to hesitancy among healthcare workers while still working towards the goal of increased vaccination. We in the bioethics and medical community should be willing to listen to our colleagues' concerns with respect. Top-down approaches aimed at "correcting" hesitancy cannot address the more fundamental issues of trust that are often at stake. Instead, there must be dialogue over time. Conversations with a trusted healthcare provider have a crucial role. ${ }^{10}$ Blaming and shaming rhetoric, whether explicit or implicit, gets us nowhere - in fact, it likely moves us backward by likely exacerbating any existing distrust or resentment that workers may hold toward their employers. ${ }^{11}$ Lastly, the onus of trust must be with institutions, not individuals. There is a lot of talk about getting 
communities of color, and Black people, particularly, to "trust" healthcare institutions and the COVID vaccines. This racializes trust and puts the burden on harmed communities rather than on institutions acting in trustworthy ways. ${ }^{12}$

Dialogue, respect, and trustworthiness must guide us even in the new era of workplace mandates. Mandates make these strategies even more important as we look toward an uncertain future. As Heidi Larson, founder of the Vaccine Confidence Project, recently said, "We should not forget that we are making people's future history now. Are people going to remember that they were treated respectfully and engaged?"13

\section{Kara Simpson}

Since the release of the vaccine for COVID-19 in late 2020, there have been robust discussions within the medical community, the media, and political arenas about vaccine hesitancy among healthcare workers. The public became aware that healthcare workers, the first group to become eligible for the vaccine, were not rushing to "take the shot."

Many people's opinions were aligned by race, ethnicity, socioeconomic status, and political affiliation. People of color were one of the first groups to be labeled vaccine hesitant as our experiences of distrust of the medical community and the politicization of the vaccine explained the low turnout. ${ }^{14}$ It was not uncommon to hear, "this vaccine just came out; let's wait and see if there are side effects." Interestingly, many people in the healthcare community and in the public did not understand why healthcare workers of color remained hesitant.

Trust is a vital component of any viable relationship, especially in the clinical realm. To have successful health outcomes, it is essential for clinicians to build trusting relationships with their patients and peers. Many people of color are distrustful towards the medical institution due to the years of systemic racism and abuses that they have experienced, witnessed, or learned about. Healthcare workers of color are not excluded from the experiences of their communities outside of work. In fact, I assert that healthcare of color may have an additional burden of hesitation because of their lived experiences of distrust in receiving care and inequality within their professional environment. These dual traumas can work in tandem to strengthen hesitancy. I assert that building trusting clinical relationships will address hesitancy over time.

Currently, many healthcare workers are worried about vaccine mandates. For a group of people that have experienced intergenerational enslavement and marginalization, mandates feel coercive and serve as a reminder of how "lesser" bodies are considered unworthy of voice, fundamental human rights, independent decision making. To call the vaccine mandate paternalistic would be an understatement.

An unintended result of vaccine mandates will be the reinforcement of hesitancy and distrust of the medical institution as trust and coercion cannot coexist. This mandate will give more power to the conspiracy theories and harm those who already do not seek or receive adequate health care because of systemic inequalities. Furthermore, mandates can also dissuade people of color from becoming healthcare workers, and others may leave the field.

In essence, vaccine hesitancy is a symptom of a much larger problem: the distrust of the medical establishment. As bioethicists, our mission should be to support interventions that foster "trustworthiness" of the institutions rather than those that cause trauma. Several organizations have proposed mask mandates and weekly testing as a measure to protect the population at large and still respect the autonomy of the unvaccinated. ${ }^{15}$ 


\section{Jennifer Breznay}

I work in a very large community teaching hospital in Brooklyn, and we were extremely hard hit by COVID in March 2020. I worked on inpatient medical units and witnessed a lot of suffering. And after nine months of fear and despair about COVID's toll, I felt tremendous frustration in December when I heard that many healthcare workers would reject the vaccine. As the co-chair of the Bioethics Committee, I drafted a statement recommending vaccination for all employees. When the draft was revised and approved by the Bioethics Committee, I began to discuss it with employees, and I appreciated different perspectives I had not heard before. In the end, rather than releasing the statement, we directed our efforts at creating a dialogue.

I also volunteer at a not-for-profit which operates seven early childhood education centers in Northern Brooklyn. The Executive Director invited me to collaborate on strategies to encourage staff vaccination, and we decided to offer a Zoom conference to 20 members of the staff. I was extremely nervous about how the audience would perceive me, a white doctor whom they did not know. I felt awkward about coming to them with an agenda. And there was also the question of whether I was an appropriate messenger compared to a person of color.

Yet, I felt like I shouldn't back away from this. So, I chose to simply disclose my discomfort at the beginning of the Zoom. I said, "Thanks for having me. You know, as a white physician, I understand you might have concerns about trusting what I say. Four hundred years of inequity and abuse by the healthcare system can create a lot of mistrust, but I'm here to try to answer your questions." Ultimately the Executive Director reported that the Zoom was successful in stimulating a lot of conversation among the staff about the vaccine. I think the critical piece is the intimate but open conversation, where you can elicit values.

\section{Ashley L. Stewart}

In the rural areas of our state, healthcare institutions are inextricably tied to their communities. Rural hospitals hire from, serve, and function in the community where they are located. Successful implementation of a vaccine roll-out in such rural areas requires explicit recognition of the role and influence of the community. After identifying issues common to the area, rural institutions can address them. Even when rural institutions find that healthcare worker concerns seem to be unique or personal, they are often related to the larger concerns of the community. ${ }^{16}$

Community-based increased vaccine hesitancy may coincide with an underlying issue, such as lack of information rather than principled or experience-based resistance. ${ }^{17}$ When the vaccines became available, rural vaccination coordinators encountered a wealth of misinformation that left many people initially undecided. Compounding this lack of information, workers expressed a sense of fear about the professional consequences of voicing concerns, especially in tight-knit communities. Many workers expressed concern about being judged merely for sharing their questions or decisions. ${ }^{18}$ They also felt that saying or doing something to promote the value of vaccination might change their relationship with members of the community where they live and work. ${ }^{19}$ As there was a fear of engaging in productive conversations, it was difficult for them to find valuable information, and the lack of information discouraged them from being vaccinated. Vaccine coordinators wanted to get information to the entire community based on the most current research and release unbiased, consistent, and timely information from sources all people in the community could trust, including from multiple sources at once. Communication must focus on answering many types of questions, which must often be done in private or anonymously. 
Where poorly supported or incorrect information is widely available, sharing objective information is crucial to turning the tide of distrust. If the healthcare community dismisses concerns or assumes that answering questions based on misinformation is a waste of time, the community-based institutions will further the distrust. Some may feel that vaccine coordinators should not address misinformation directly, yet avoidance has been widely unsuccessful. ${ }^{20}$ Being respectful and non-judgmental in answering questions posed by people who do not know what is true can be hard, but in rural communities, answering completely and honestly without judgment is a critical component of any effort to inform people. Telling people to get vaccinated "for the greater good" can sound the same as being told not to get a vaccine because it is "bad" if both sources of information fail to back up their claims. Ultimately rural institutions are respected because they are a resource to their communities, a priority we must preserve.

It is also critical to treat everyone respectfully regardless of vaccine status. ${ }^{21}$ People may perceive mandates, divisive policies, or disrespectful treatment of people based on vaccination status as discriminatory or coercive, weakening the appeal of vaccination. Such practices may make people less trusting and more anchored to their position as they come to see vaccination proponents as untrustworthy or authoritarian. We must work to maintain respect for human autonomy. Using unethical means to achieve even a just end will not lead to a "greater good" but rather to the perception that people in positions of authority would achieve a result "by any means necessary."

\section{David N. Hoffman}

The central moral quandary that arises whenever vaccine hesitancy among healthcare workers is discussed is whether workers who refuse to get vaccinated should or could be fired. We should clarify that we are applying a definition of mandate in the employment context for private employers, the violation of which results in loss of employment. Government-controlled provider organizations are just now weighing in on this topic and are generally pursuing strategies that impose periodic, usually weekly, testing requirements for those workers who decline to get vaccinated.

In the private sector, employers can require their employees to do a great many things as a condition of employment, and one of them is to get vaccinated against COVID -19. In the most prominent case to date, just such a mandate gave rise to a lawsuit in Texas involving Houston Methodist Hospital. In that case, 170 employees asserted that an employer should not be allowed to force them to get vaccinated. The judge held that, while no employer can force an employee to get vaccinated, no employer is obligated to continue the employment of any employee who declines to follow rules established by that employer, including the obligation to get vaccinated. ${ }^{22}$

In Texas, what the judge said is you are not being forced to get vaccinated, but your employer is allowed to set limits and conditions on employment, including vaccination. Employees do not have an obligation to get vaccinated, but they also have no right to their jobs. That is because of a widely misunderstood legal concept: "employment at will." Employment at will sounds like a rule that employees can do what they want at work, but in fact, employment at will means only that you can quit your job whenever you want (we do not permit indentured servitude). At the same time, your employer can fire you at any time, for any reason or no reason, unless the reason is a pretext and involves one of the protected statuses (race, color, religion, sex or national origin, and in some jurisdictions gender orientation, gender identity).

Generally, any employers, including hospitals, can decide that if someone is not willing to get a vaccination, or if they are not willing to complete sexual harassment training or participate in the hospital's infection 
control program, that is the employee's right, but it will mean that an employer can similarly decline to continue providing employment.

The evolution of this hesitancy discussion will be influenced by the narrower debate playing out in the court of public opinion, and the courts of law, over the enforceability of New York's recently enacted vaccine mandate. Regardless of whether that mandate survives, with or without medical and religious exemptions, healthcare employers will be left with a profound ethical dilemma. At the end of all the litigation, if there is a religious exemption, employers will always be burdened with the responsibility to determine whether an individual employee has asserted a genuine and sincere religious objection to vaccination and whether the employer is able to provide an accommodation that is safe and effective in protecting the interests of co-workers and patients. The anticipated federal mandate, which reportedly will have a test/mask alternative, will only make this ethical task more challenging.

This leads to the final point in this analysis, which is that while private employers, including hospitals, can deprive an individual of their employment if those individuals refuse to get vaccinated, just because an employer can do so does not mean it should do so. ${ }^{23}$

\footnotetext{
${ }^{1}$ MacDonald NE. Vaccine hesitancy: Definition, scope and determinants. Vaccine. 2015;33(34):4161-4164. doi:10.1016/j.vaccine.2015.04.036

2 Larson HJ, de Figueiredo A, Xiahong Z, et al. The State of Vaccine Confidence 2016: Global Insights Through a 67-Country Survey. EBioMedicine. 2016;12:295-301. doi:10.1016/j.ebiom.2016.08.042

${ }^{3}$ Larson H. Stuck: How Vaccine Rumors Start - and Why They Don't Go Away. Oxford University Press; 2020; Benjamin R. Informed Refusal: Toward a Justice-based Bioethics. Sci Technol Hum Values. 2016;41(6):967-990. doi:10.1177/0162243916656059

${ }^{4}$ Deepa Shivaram, In The Fight Against COVID, Health Workers Aren't Immune To Vaccine Misinformation
}

September 18, 2021. NPR Special Series: The Coronavirus. https://www.npr.org/2021/09/18/1037975289/unvaccinated-covid19-vaccine-refuse-nurses-heath-care-workers

${ }^{5}$ Crane JT, Pacia D, Fabi R, Neuhaus C, and Berlinger N. Advancing Covid vaccination equity at Federally Qualified Health Centers: A rapid qualitative review. Accepted and awaiting publication at JGIM.

${ }^{6}$ Ashley Kirzinger. "KFF/The Washington Post Frontline Health Care Workers Survey - Vaccine Intentions." KFF, 22 Apr. 2021, https://www.kff.org/report-section/kff-washington-post-frontline-health-care-workers-survey-vaccine-intentions/.

7 Johanna Crane, Samuel Reis-Dennis and Megan Applewhite. "Prioritizing the '1a': Ethically Allocating Scarce Covid Vaccines to Health Care Workers." The Hastings Center, 21 Dec. 2020, https://www.thehastingscenter.org/prioritizing-the-1a-ethicallyallocating-covid-vaccines-to-health-care-workers/.

8 "I'm Not an Anti-Vaxxer, but...' US Health Workers' Vaccine Hesitancy Raises Alarm." The Guardian, Guardian News and Media, 10 Jan. 2021, https://www.theguardian.com/world/2021/jan/10/coronavirus-covid-19-vaccine-hesitancy-us-health-workers.

${ }^{9}$ Gerson M. If you are healthy and refuse to take the vaccine, you are a free-rider. Washington Post. April 15, 2021.

${ }^{10}$ Crane JT, Pacia D, Fabi R, Neuhaus C, and Berlinger N. Advancing Covid vaccination equity at Federally Qualified Health Centers: A rapid qualitative review. Accepted and awaiting publication at JGIM.

11 Larson H. Stuck : How Vaccine Rumors Start - and Why They Don't Go Away. Oxford University Press; 2020. 
12 Benjamin R. Race for Cures: Rethinking the Racial Logics of 'Trust' in Biomedicine. Sociology Compass. 2014;8(6):755-769. doi:10.1111/soc4.12167; Warren RC, Forrow L, David Augustin Hodge S, Truog RD. Trustworthiness before Trust - Covid-19 Vaccine Trials and the Black Community. N Engl J Med. Published online October 16, 2020. doi:10.1056/NEJMp2030033

13 Offri D. Heidi Larson, Vaccine Anthropologist. New Yorker. Published online June 12, 2021. Accessed August 11, 2021. https://www.newyorker.com/science/annals-of-medicine/heidi-larson-vaccine-anthropologist

${ }^{14}$ Razai M S, Osama T, McKechnie D G J, Majeed A. Covid-19 Vaccine Hesitancy Among Ethnic Minority Groups. BMJ 2021; 372 :n513 doi:10.1136/bmj.n513

15 Dasgupta, Sharoda, et al. "Differences in Rapid Increases in County-Level COVID-19 Incidence by Implementation of Statewide Closures and Mask Mandates - United States, June 1-September 30, 2020." Annals of Epidemiology, vol. 57, Sept. 2021, pp. 4653., https://doi.org/10.1016/j.annepidem.2021.02.006.

16 Do, Tuong Vi C et al. "COVID-19 Vaccine Acceptance Among Rural Appalachian Healthcare Workers (Eastern Kentucky/West Virginia): A Cross-Sectional Study." Cureus vol. 13,8 e16842. 2 Aug. 2021, doi:10.7759/cureus.16842;

Danabal, K.G.M., Magesh, S.S., Saravanan, S. et al. Attitude towards COVID 19 vaccines and vaccine hesitancy in urban and rural communities in Tamil Nadu, India - a community-based survey. BMC Health Serv Res 21, 994 (2021). https://doi.org/10.1186/s12913-021-07037-4

17 Scott C. Ratzan MD, MPA, MA, Lawrence O. Gostin JD, Najmedin Meshkati PhD, CPE, Kenneth Rabin PhD \& Ruth M. Parker MD (2020) COVID-19: An Urgent Call for Coordinated, Trusted Sources to Tell Everyone What They Need to Know and Do, Journal of Health Communication, 25:10, 747-749, DOI: 10.1080/10810730.2020.1894015

18 Huang, Pien. "Some Health Care Workers Are Wary of Getting COVID-19 Vaccines." NPR, NPR, 1 Dec. 2020, https://www.npr.org/sections/health-shots/2020/12/01/940158684/some-health-care-workers-are-wary-of-getting-covid-19vaccines.

Portnoy, Jenna. "Several Hundred Virginia Health-Care Workers Have Been Suspended or Fired over Coronavirus Vaccine Mandates." The Washington Post, WP Company, 4 Oct. 2021, https://www.washingtonpost.com/local/covid-vaccine-mandatehospitals-virginia/2021/10/01/b7976d16-21ff-11ec-8200-5e3fd4c49f5e_story.html.

19 Jennifer A. Lueck \& Alaina Spiers (2020) Which Beliefs Predict Intention to Get Vaccinated against COVID-19? A Mixed-Methods Reasoned Action Approach Applied to Health Communication, Journal of Health Communication, 25:10, 790-798, DOI: 10.1080/10810730.2020.1865488

20 Lockyer, Bridget, et al. "Understanding Covid-19 Misinformation and Vaccine Hesitancy in Context: Findings from a Qualitative Study Involving Citizens in Bradford, UK." Health Expectations, vol. 24, no. 4, 4 May 2021, pp. 1158-1167., https://doi.org/10.1101/2020.12.22.20248259.

Scott C. Ratzan \& Ruth M. Parker (2020) Vaccine Literacy-Helping Everyone Decide to Accept Vaccination, Journal of Health Communication, 25:10, 750-752, DOI: 10.1080/10810730.2021.1875083.

21 Zimmerman, Anne. Columbia Academic Commons, 2020, Toward a Civilized Vaccination Discussion: Abandoning the False Assumption That Scientific Goals Are Shared by All, https://academiccommons.columbia.edu/doi/10.7916/d8-rzh0-1f73.

22 Bridges, et al v. Houston Methodist Hospital et al, https://docs.justia.com/cases/federal/districtcourts/texas/txsdce/4:2021cv01774/1830373/18

${ }^{23}$ David N. Hoffman, "Vaccine Mandates for Health Care Workers Raise Several Ethical Dilemmas," Hasting Center Bioethics Forum. August 2021. https://www.thehastingscenter.org/vaccine-mandates-for-health-care-workers-raise-several-ethicaldilemmas/ 